\title{
Applications of Hadamard Transform-Gas Chromatographyl Mass Spectrometry (HT-GC/MS) to the Detection of Pesticides in Rice
}

\author{
Cheng-Huang Lin and Chien-Hung Lin \\ Department of Chemistry, National Taiwan Normal University, Taipei
}

Taiwan

\section{Introduction}

The levels of pesticide residues in rice and the standard operating procedures (SOP) for these are often stipulated in many countries (Pareja et al., 2011a; Pareja et al., 2011b). The conventional analysis of pesticide residues is a labor intensive procedure, since it is necessary to cover a wide range of different chemicals, using a single procedure. These traditional labor intensive extraction methods, such as liquid-liquid extraction, solidphase extraction and accelerated solvent extraction are still used, whereas the use of the Quick Easy Cheap Effective Rugged and Safe (QuEChERS) pesticide multiresidue method is economic and fast (Pareja et al., 2011b; Mastovska et al., 2010; García-Reyes et al., 2009). It has been validated for the extraction of 80 pesticides belonging to various chemical classes from various types of representative commodities with low lipid contents. However, supercritical fluid extraction (SFE) is also a popular method for pesticide extraction from foods (Kim et al., 1998; Izquierdo et al., 1996; Anastassiades and Schwack, 1998; Eller and Lehotay, 1997; Lehotay, 1997; Bernal et al., 2008; France et al., 1991; Goli et al., 1997). The advantages of SFE are well-known by now, including savings in labor, operational costs, laboratory space, waste minimization and increased selectivity versus traditional methods (Wang and Chang, 1998; Giddings et al., 1968; Hawthorne, 1990). When using SFE, in many cases the extracts should be further examined by GC/MS (gas chromatography/mass spectrometry) or HPLC/MS (high-performance liquid chromatography/mass spectrometry) to achieve the necessary selectivity and sensitivity for the different classes of compounds under detection (Hansen et al., 1995; Blanch et al., 1995; Jacques et al., 2007; Seger et al., 2004; Stolker et al., 2003). In this work, we developed a novel method by combining an on-line sample SFE collection system and the Hadamard transform GC/MS (HT-GC/MS) method for the extraction/detection of pesticide in rice (Fan et al., 2010; Johansen et al., 1994; Fuoco et al., 1997; Aguilera et al., 2005; Gmuer et al., 1987). The methodology of HT-GC/MS and the design of an on-line SFE sample collection system are demonstrated. Details of the experimental conditions for the determination of pesticides in rice are also reported herein. 


\section{Experimental}

\subsection{Reagents}

Diazinon, parathion-methyl and chlorpyrifos were purchased from Sigma-Aldrich (St. Louis, MO, USA). All the other chemicals and gases were of analytical grade and were purchased from commercial sources.

\subsection{Apparatus}

A gas chromatograph/mass spectrometer (GC 6890 equipped with 5973 mass selective detector; Hewlett-Packard, Avondale, PA, USA) was used in this study. A novel type of Hadamard-injector was prepared in our laboratory; it can be controlled via a personal computer through a PCI 6221 device (National Instruments, USA), according to a series of Hadamard codes. A commercial supercritical fluid extractor $\left(\mathrm{CO}_{2}\right.$ pump, PU-1580$\mathrm{CO}_{2}$ /HPLC pump, PU-2080; JASCO, Japan) was used to the extract the spiked pesticides. The HT-GC chromatograms were calculated using the LabVIEW program.

\section{Methodology}

\subsection{Hadamard transform (HT)}

The Hadamard transform (HT) technique has been applied in a variety of fields, including time-of-flight mass spectrometry (Brock et al., 1998; Fernández et al., 2002; Trapp et al., 2004; Fernández et al., 2001), Raman spectrometry (Treado et al., 1990; DeVerse et al., 2000; DeVerse et al., 1999), fluorescence imaging (Chen et al., 1995; Mei et al., 1996; Tang et al., 2002; Hassler et al., 2005) ion mobility spectrometry (Clowers et al., 2006; Szumlas et al., 2006), and NMR (Kubo et al., 1996; Feliz et al., 2006). In addition, the application of the cross correlation technique to chromatographic separation was first proposed by Izawa and coworkers. A Hadamard matrix on the order of $\mathrm{n}, H_{n}$, is an $n \times n$ of +1 's and -1 's with the property of the scalar product of any two distinct rows being 0 . Thus, $H_{n}$ must satisfy the following equation,

$$
\mathrm{H}_{\mathrm{n}} \mathrm{H}_{\mathrm{n}}^{\mathrm{T}}=\mathrm{H}_{\mathrm{n}}^{\mathrm{T}} \mathrm{H}_{\mathrm{n}}=\mathrm{nI}_{\mathrm{n}}
$$

where $H_{n}{ }^{T}$ is the transpose of $H_{n}$ and $I_{n}$ is the unit matrix on the order of $\mathrm{n}$. A fundamental equation of the Hadamard transformation is given by

$$
[\eta]=[S] \times[C]
$$

where $\eta$ is a series of data, i.e., the observed chromatogram, encoded by a cyclic S-matrix, $S$, which is the $(n-1) \times(n-1)$ matrix consisting of "zero" and "one" elements, and $C$ is a series of data representing a chromatogram. A cyclic S-matrix on the order of $(n-1)$ is obtained by omitting the first row and column of $H_{n}$ and then changing +1 's to 0 's and -1 's to 1 's. To encode the chromatogram, $C$, a sample and eluent are introduced into a column according to the PRBS (pseudorandom binary sequence) derived from the cyclic S-matrix. When the elements of the PRBS are "one" and "zero," sample and eluent plugs are introduced into the column, respectively. As a result, the encoded chromatogram, $\eta$, is obtained. The encoded chromatogram is decoded to the chromatogram, $C$, by multiplying an inverse matrix of $S, S^{-1}$, as follows.

$$
[C]=[S]^{-1} \times[\eta]
$$


Consequently, the decoded chromatogram shows improvement in the $\mathrm{S} / \mathrm{N}$ ratio (Fellgett advantage). In both correlation and HT methods, the key technology, based on multiple input techniques according to PRBS, is the injection device, which permits the continuous introduction of a sample. Multiple injection devices for GC have also been developed for correlation GC, in which the solenoid valve (Smit, 1970; Annino and Bullock, 1973), cylindrical slide valve (Kaljurand and Küllik, 1979), and fluidic logic gate (Annino et al., 1979) were used. Conversely, in correlation LC, the input signals modulated by PRBS were generated by valve systems (Lub et al., 1978; Smit et al., 1980; Laeven et al., 1983; Mars and Smit, 1990; Kaljurand et al., 1992) and by an electrochemical concentration modulator (Engelsma et al., 1990).

\subsection{Hadamard-injector}

A schematic drawing is shown in Figure 1. The developed Hadamard-injector permits a pressurized gas or pressurized liquid to be injected into a separation column according to a pseudorandom binary sequence (PRBS), i.e. a Hadamard code. In fact, it was made by

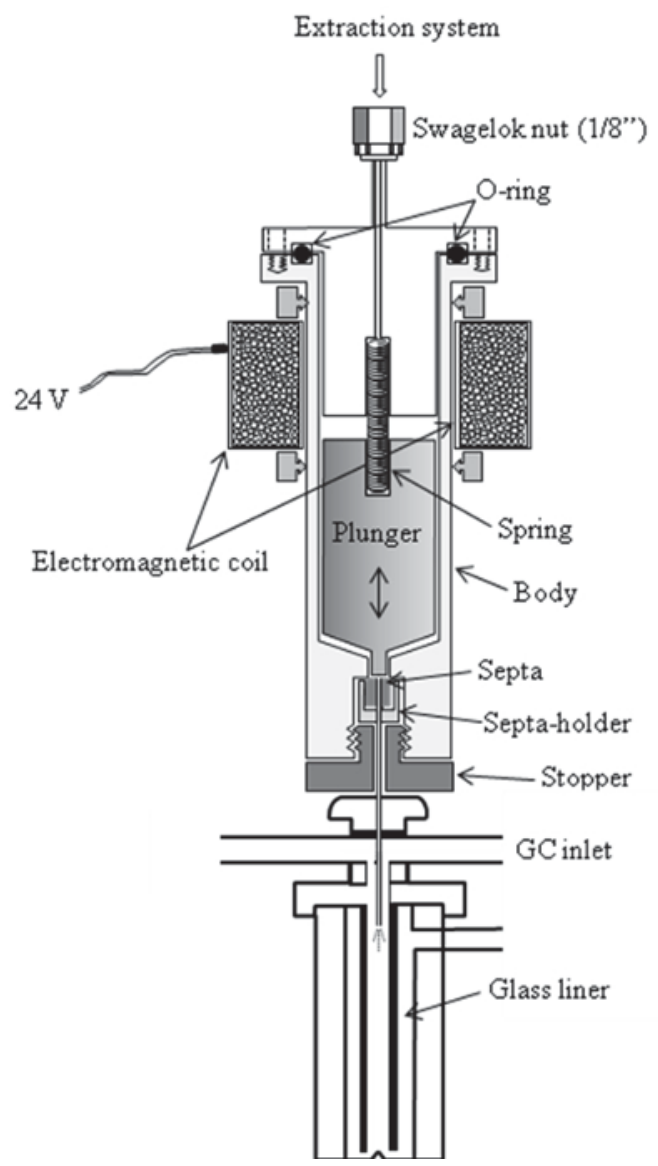

Fig. 1. A schematic drawing of the Hadamard injector used in this study. 
modifying a regular pulse nozzle (Lin and Imasaka, 1993). Instead of a pinhole, which is used in general pulse nozzles, a piece of a capillary was used for the introduction of the pressurized sample solution (I.D., $50 \mu \mathrm{m} ; 8 \mathrm{~cm}$ in length). The body of the Hadamard-injector was made of brass; the plunger had a diameter of $9.5 \mathrm{~mm}$ and a length of $34 \mathrm{~mm}$. A $24 \mathrm{~V}$ electromagnetic coil and the spring were removed from a solenoid valve (SMC model VX2110: 0 1.5 MPa, Japan), respectively, and used directly. A septa-BTO (Item No. 298735) was inserted into a brass holder, which was used to firmly attach the capillary and prevent gas or liquid leaks, and was sealed with a brass stopper. The Hadamard-injector can be heated and directly inserted into the GC inlet; the injection volume of the sample solution can be adjusted by changing the background pressure (nitrogen gas), the inner diameter of the capillary, the capillary length and the injection time to achieve a micro-controlled injection. During the sample injection process, a personal computer was used to rapidly turn the Hadamard-injector on and off through the PCI 6221 device, according to a series of Hadamard codes, leading to the introduction of the pressurized sample solution through the capillary into the GC column. The injection volume of the pressurized sample solution can be adjusted by changing the background pressure (nitrogen gas), the inner diameter of the capillary, capillary length, and injection time. Figure 2 shows the relationship between the injected volume and injection time based on various background pressures (A, for pressurized gas: $1.3 \sim 1.8 \mathrm{Kg} / \mathrm{cm}^{2}$; B, for pressurized liquid: $1.5 \sim 3 \mathrm{Kg} / \mathrm{cm}^{2}$, respectively). Herein, the injected volume was recognized by means of a gas drainage method (Figure 2A) and by weighing the collected liquid (Figure 2B), respectively. As can be seen in Figure 2A (for pressurized gas), when the injection time was adjusted in the range of $1 \sim 3 \mathrm{~s}$, the injection volume can be controlled from 0.3 to $4.2 \mu \mathrm{L}$; in Figure $2 \mathrm{~B}$ (for a pressurized liquid), when the injection time was adjusted in the range of $0.1 \sim 1 \mathrm{~s}$, the injection volume can be controlled from 0.04 to $0.3 \mu \mathrm{L}$. It should be noted that both show very good linear relationships. The RSD (related standard deviation) values of within-day and betweenday were determined to $0.24 \sim 0.38 \%$ and $0.27 \%$, respectively, indicating the stability and reproducibility of the procedure. Furthermore, the sample injection time, volume and split-ratio were investigated in detail during GC separation experiments.

\section{Results and discussion}

Figure 3 shows a schematic diagram of the on-line SFE/HT-GC/MS system. This system consists of a commercial SFE instrument, a commercial GC/MS, a holding tank and the Hadamard-injector. A $2.0 \mathrm{~g}$ sample of rice, obtained from a local supermarket, was spiked with three different pesticides (diazinon, chlorpyrifos and parathion-methyl, $30 \mu \mathrm{g}$ each). The rice sample had first been subjected to a typical GC/MS method to confirm the absence of pesticide contaminants. The extraction liquid was $1.5 \mathrm{~mL}$ of acetonitrile. A $0.8 \mathrm{~g}$ quantity of glass beads was also placed in the holding tank to suppress bubbling. The $\mathrm{CO}_{2}$ pressure was set at $20.3 \mathrm{MPa}$ so as to extract the pesticides at a flow rate at $1 \mathrm{~mL} / \mathrm{min}$ (oven temperature, $50{ }^{\circ} \mathrm{C}$ ). After adding $15 \mathrm{~mL}$ of supercritical $\mathrm{CO}_{2}$ fluid, the liquid was slowly passed through the spiked rice sample at a constant rate, the extracts were passed through a filter $(0.45 \mu \mathrm{m})$ and then directly injected into the GC column by a personal computer, which turned the Hadamard-injector on and off, quickly, based on the Hadamard codes. The optimized conditions were a background pressure of $3 \mathrm{Kg} / \mathrm{cm}^{2}$ and an injection time of $0.2 \mathrm{~s}$. The injection volume was estimated to be $\sim 66 \mathrm{~nL}$ for a single injection. 

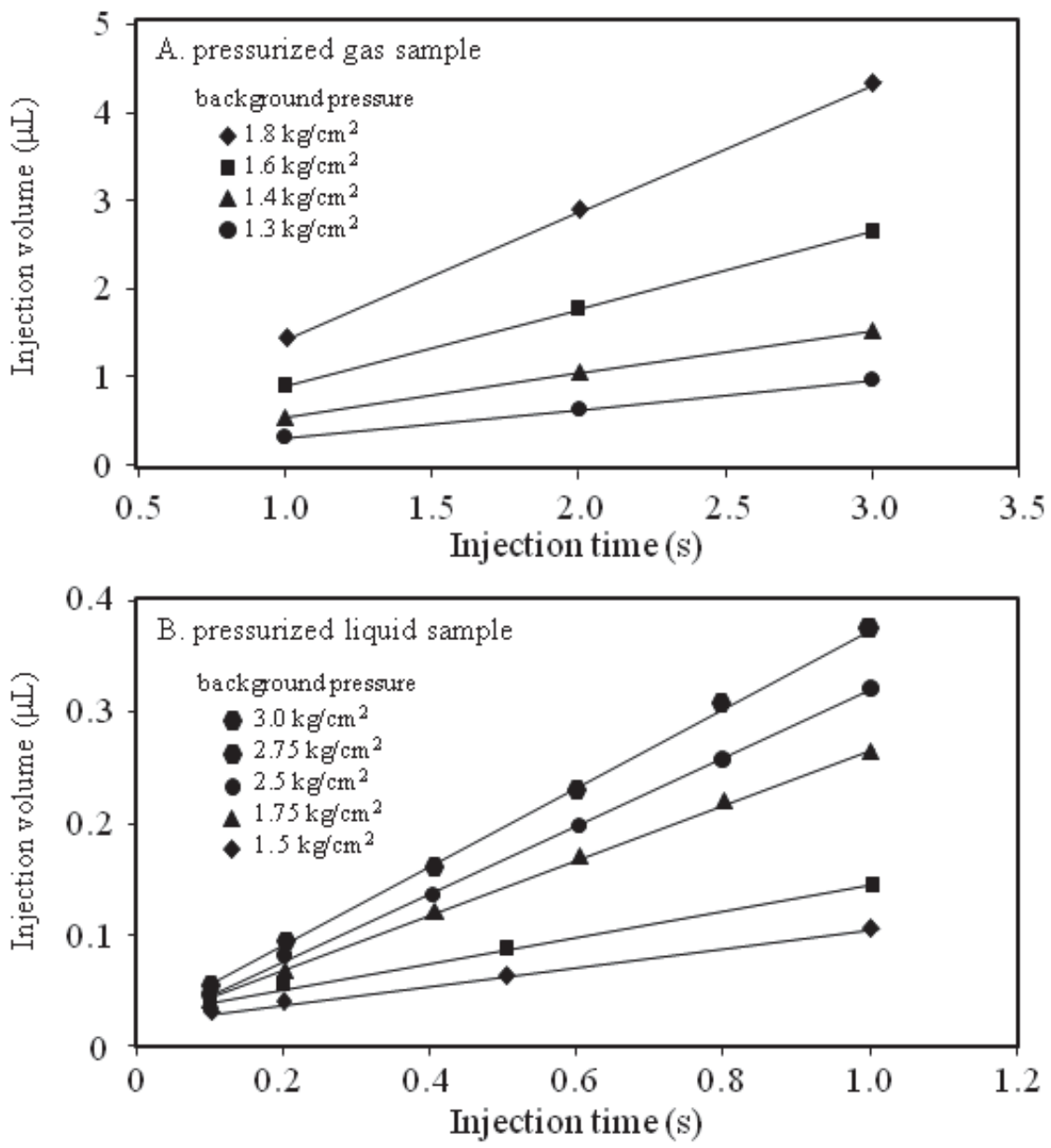

Fig. 2. Relationships between injected volume and injection time based on various background pressures (A, pressurized gas: $1.3 \sim 1.8 \mathrm{Kg} / \mathrm{cm}^{2}$; B, pressurized liquid: $1.5 \sim 3$ $\mathrm{Kg} / \mathrm{cm}^{2}$, respectively).

Figure 4 shows typical GC/MS chromatograms for parathion-methyl standard by means of single injection (frame A) and Hadamard injection (frame B). The concentration level was 20 $\mu \mathrm{g} / 1 \mathrm{~mL}$ acetonitrile. In the case of single injection, injection volume was $66 \mathrm{~nL}$ (absolute amount, $1.3 \mathrm{ng}$ ). The findings show that the $\mathrm{S} / \mathrm{N}$ ratio of the chromatogram was relatively poor in frame A. However, under the same experimental conditions, when the Hadamard injection was performed (as shown in frame B; matrix order, $\mathrm{n}=255$ ), and each injection volume was still $66 \mathrm{~nL}$, the S/N ratio was dramatically improved. The inset in frame B shows the details of raw data before the inverse Hadamard transformation (chromatogram a, whole chromatogram; chromatogram $b$, portion chromatogram of $n=127 \sim 238$ ) and the Hadamard code (chromatogram c, $\mathrm{n}=127 \sim 238$ ). As can be seen, chromatograms $\mathrm{b}$ and $\mathrm{c}$ are quite matched, and for this reason, the $\mathrm{S} / \mathrm{N}$ ratio improved as excepted. 


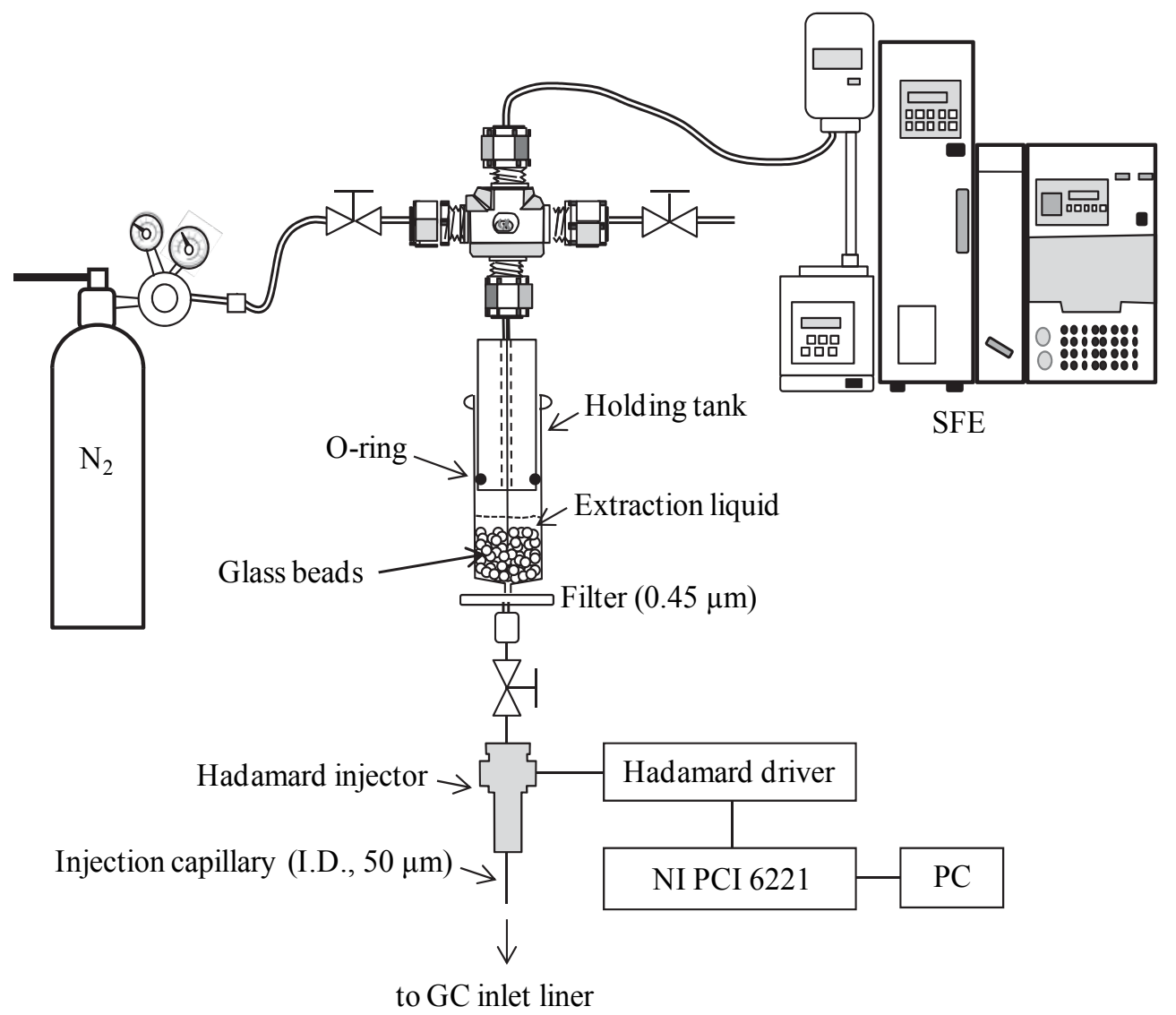

Fig. 3. A schematic diagram of the on-line SFE/HT-GC/MS system.

When analyzing a mixture of different pesticides, the use of Hadamard transform is also helpful to improve the $\mathrm{S} / \mathrm{N}$ ratio. In this case, three types of pesticides (diazinon, parathionmethyl and chlorpyrifos) were spiked in the sample rice. Figure 5 shows typical HT-GC/MS chromatograms of the on-line SFE extracts from the spiked rice sample. Herein, the SIM mode was used (ion peaks at $m / z=125,137$ and 199 were selected for monitoring). Chromatograms a and $\mathrm{b}$ show the results obtained for a single injection and a Hadamard injection (matrix order, $\mathrm{n}=255$ ), respectively. As can be seen, the $\mathrm{S} / \mathrm{N}$ ratio is again substantially improved. The detected peaks are also completely consistent with the theoretical prediction. Table 1 shows the relationship between the enhancement in S/N ratios and mass conditions for analysis based on on-line supercritical fluid extraction/HTGC/MS methods (SIM mode was used; $\mathrm{m} / \mathrm{z}=125,137,199$ for diazinon, chlorpyrifos and parathion-methyl, respectively). The results indicate that the on-line SFE/Hadamardinjector described herein also permits precise multiple injections and that it can be used for the determination of actual samples. 


\section{A. Single injection}

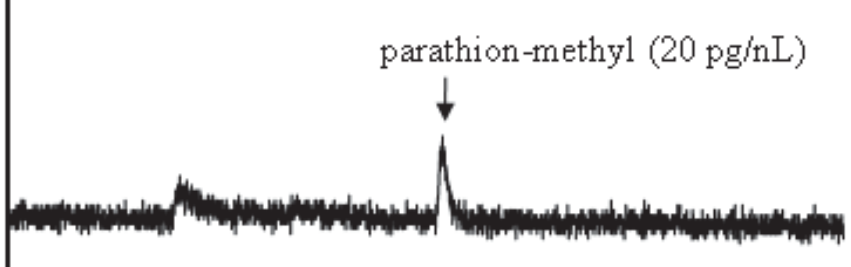

B. Hadamard injection $(\mathrm{n}=255)$

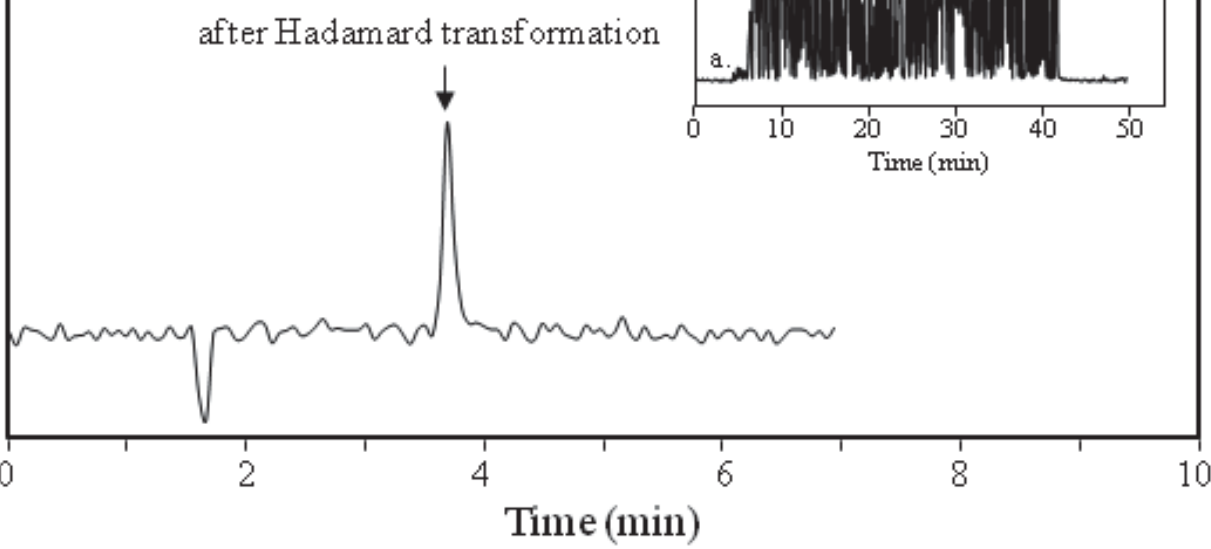

Fig. 4. Typical GC/MS chromatograms for parathion-methyl standard; concentration level, 20 $\mu \mathrm{g} / 1 \mathrm{~mL}$ acetonitrile. In frame A, chromatogram was obtained by single injection (injected volume, $66 \mathrm{~nL}$; absolute amount, $1.3 \mathrm{ng}$ ). In frame B, chromatogram was obtained by Hadamard injection (Hadamard matrix, $\mathrm{n}=255$; each injection volume, $66 \mathrm{~nL}$; total injection volume, $16.8 \mu \mathrm{L}$ ). The inset in frame B shows the details of raw data before the inverse Hadamard transformation (chromatogram a, whole chromatogram; chromatogram b, portion chromatogram of $n=127 \sim 238$ ) and the Hadamard code (chromatogram $\mathrm{c}, \mathrm{n}=127 \sim 223$ ). 


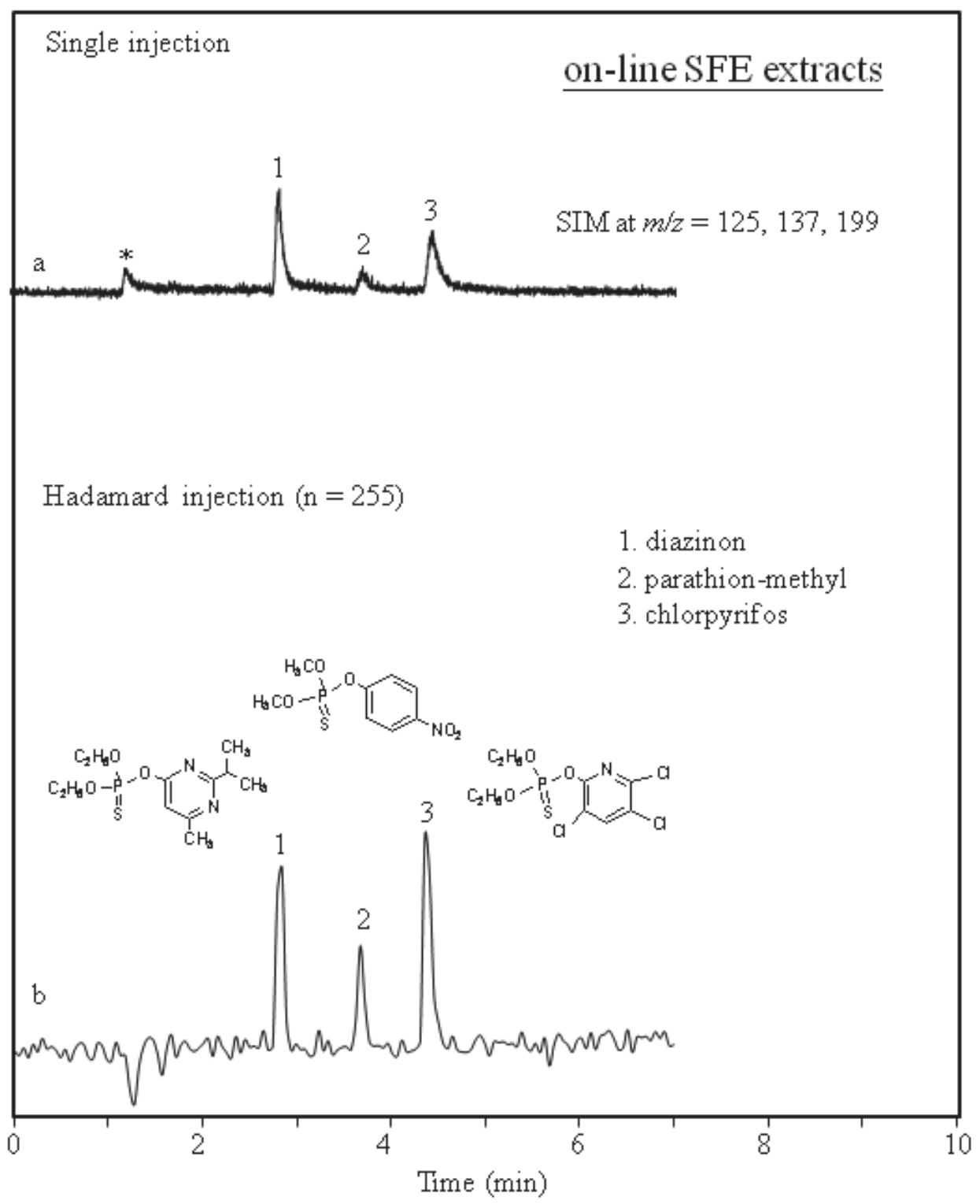

Fig. 5. Typical GC/MS chromatograms of the on-line SFE extracts based on the SIM mode. Chromatograms a and b show single-injection and Hadamard injection (order of matrix, 255), respectively. Diazinon, chlorpyrifos and parathion-methyl (30 $\mu \mathrm{g}$ of each) were spiked to $2.0 \mathrm{~g}$ rice. Inset, the raw data shown before inverse Hadamard transformation. The solvent peak is indicated by "*". 


\begin{tabular}{lc}
\hline Matrix order & Enhancement of S/N ratio \\
\hline & theoretical \\
255 & 8.02 \\
\hline & observed \\
diazinon & 6.8 \\
chlorpyrifos & 4.3 \\
parathion-methyl & 7.6 \\
\hline
\end{tabular}

The enhancement of the $\mathrm{S} / \mathrm{N}$ ratio was calculated as the ratio of $\mathrm{S} / \mathrm{N}$ values obtained in the chromatograms, measured by HT-GC/MS and a single injection method.

Table 1. Relationship between the enhancement in $\mathrm{S} / \mathrm{N}$ ratios and mass conditions for analysis based on on-line supercritical fluid extraction/HT-GC/MS methods (SIM mode was used; $\mathrm{m} / \mathrm{z}=125,137,199$ for diazinon, chlorpyrifos and parathion-methyl, respectively).

\section{Conclusion}

In this study, we developed novel Hadamard-injectors coupled with sample collection systems. The SFE system was successfully interfaced with the Hadamard-injector and the extracts were successfully collected. The utility of the method was demonstrated using some representative pesticides as model compounds. The device permitted continuous and precise sample injections in HT-GC/MS, resulting in a substantial improvement in S/N ratios through the application of the Hadamard transformation. The enhancement factors for the $\mathrm{S} / \mathrm{N}$ ratios were matched with the theoretical values. Thus, this method has a variety of applications and could potentially be used in practical trace analysis.

\section{Acknowledgment}

This work was supported by grants from the National Science Council of Taiwan under Contracts of No. NSC 95-2113-M-003-016-MY3.

\section{References}

Anastassiades, M. and Schwack, W. (1998). Analysis of carbendazim, benomyl, thiophanate methyl and 2,4-dichlorophenoxyacetic acid in fruits and vegetables after supercritical fluid extraction. J. Chromatogr. A. 825. 45-54.

Aguilera, A., Rodriäguez, M., Brotons, M., Boulaid, M. and Valverde A. (2005). Evaluation of supercritical fluid extraction/aminopropyl solid-phase "in-line" cleanup for analysis of pesticide residues in rice. J. Agric. Food Chem. 53. 9374-9382.

Annino, R. and Bullock, E.L. (1973). Continuous chromatographic analysis using a pseudo random sample switching function. Anal. Chem. 45. 1221-1227.

Bernal, J.L., Nozal, M.J., Toribio, L., Diego, C., Mayo, R. and Maestre R. (2008). Use of supercritical fluid extraction and gas chromatography-mass spectrometry to obtain amino acid profiles from several genetically modified varieties of maize and soybean. J. Chromatogr. A. 1192. 266-272. 
Blanch, G.P., Reglero, G. and Herraiz M.J. (1995). Analysis of wine aroma by off-line and online supercritical fluid extraction-gas chromatography. Agric. Food Chem. 43. 12511258.

Brock, A., Rodriguez, N. and Zare, R.N. (1998). Hadamard transform time-of-flight mass spectrometry. Anal. Chem. 70. 3735-3741.

Chen, G., Mei, E., Gu, W., Zeng, X. and Zeng, Y. (1995). Instrument for Hadamard transform three-dimensional fluorescence microscope image analysis. Anal. Chim. Acta. 300. 261-267.

Clowers, B.H., Siems, W.F., Hill, H.H. and Massick, S.M. (2006). Hadamard transform ion mobility spectrometry. Anal. Chem. 78. 44-51.

DeVerse, R.A., Hammaker, R.M. and Fateley, W.G. (2000). An improved Hadamard encoding mask for multiplexed Raman imaging using single channel detection. J. Mol. Struct. 521. 77-88.

DeVerse, R.A., Hammaker, R.M. and Fateley, W.G. (1999). Hadamard transform Raman imagery with a digital micro-mirror array. Vib. Spectrosc. 19. 177-186.

Eller, K.I. and Lehotay, S.J. (1997). Evaluation of hydromatrix and magnesium sulfate drying agents for supercritical fluid extraction of multiple pesticides in produce. Analyst. 122. 429-435.

Engelsma, M., Louwerse, D.J., Boelens, H.F.M., Kok, W.T. and Smit, H.C. (1990). Correlation ion chromatography with indirect UV detection. Anal. Chim. Acta. 228. 209-227.

France, J.E., King, J.W. and Snyder, J.M. (1991). Supercritical fluid-based cleanup technique for the separation of organochlorine pesticides from fats. J. Agric. Food Chem. 39. 1871-1874.

Fan, Z., Lin, C.H., Chang, H.W., Kaneta, T. and Lin, C.H. (2010). Design and application of Hadamard-injectors coupled with gas and supercritical fluid sample collection systems in Hadamard transform-gas chromatography/mass spectrometry. J. Chromatogr. A. 1217. 755-760.

Fuoco, R., Ceccarini, A., Onor, M. and Lottici, S. (1997). Supercritical fluid extraction combined on-line with cold-trap gas chromatography/mass spectrometry. Anal. Chim. Acta. 346. 81-86.

Fernández, F.M., Vadillo, J.M., Kimmel, J.R., Wetterhall, M., Markides, K., Rodriguez, N. and Zare, R.N. (2002). Hadamard transform time-of-flight mass spectrometry: a high-speed detector for capillary-format separations. Anal. Chem. 74. 1611-1617.

Fernández, F.M., Vadillo, J.M., Engelke, F., Kimmel, J.R. and Zare, R.N. (2001). Effect of sequence length, sequence frequency, and data acquisition rate on the performance of a Hadamard transform time-of-flight mass spectrometer. J. Am. Soc. Mass Spectrom. 12. 1302-1311.

Feliz, M., García, J., Aragón, E. and Pons, M. (2006). Fast 2D NMR ligand screening using Hadamard spectroscopy. J. Am. Chem. Soc. 128. 7146-7147.

García-Reyes, J.F., Jackson, A.U., Molina-Díaz, A. and Cooks, R.G. (2009). Desorption Electrospray Ionization Mass Spectrometry for Trace Analysis of Agrochemicals in Food. Anal. Chem. 81. 820-829.

Goli, D.M., Locke, M.A. and Zablotowick, R.M. (1997). Supercritical fluid extraction from soil and HPLC analysis of cyanazine herbicide. J. Agric. Food Chem. 45. 1244-1250.

Giddings, J.C., Myers, M.N., McLaren, L. and Keller, R.A. (1968). High pressure gas chromatography of nonvolatile species. Science. 162. 67-73. 
Gmuer, W., Bosset, J.W. and Plattuer, E. (1987). Direct coupling of supercritical fluid extraction to capillary supercritical fluid chromatography. II. Construction of a prototype and examples of application. J. Chromatogr. A. 388. 335-349.

Hawthorne, S.B. (1990). Analytical-scale supercritical fluid extracrion. Anal. Chem. 62. 633A642A.

Hansen, K.J., Cravens, E., Sievers, R.E. and Hansen, B.N. (1995). Supercritical fluid extraction-gas chromatographic analysis of organic compounds in atmospheric aerosols. Anal. Chem. 67. 3541-3549.

Hassler, K., Anhut, T. and Lasser, T. (2005). Time-resolved Hadamard fluorescence imaging. Appl. Opt. 44. 7564-7572.

Izquierdo, A., Tena, M.T., Luque de Castro, M.D. and Valcarcel, M. (1996). Supercritical fluid extraction of carbamate pesticides from soils and cereals. Chromatographia. 42. 206-212.

Jacques, R.A., Santos, J.G., Dariva, C., Oliveira, J.V. and Caram, E.B. (2007). GC/MS characterization of mate tea leaves extracts obtained from high-pressure $\mathrm{CO}_{2}$ extraction. J. Supercrit. Fluids. 40. 354-359.

Johansen, H.R., Becher, G. and Greibrokk, T. (1994). Determination of planar PCBs by combining on-line SFE-HPLC and GC-ECD or GC/MS. Anal. Chem. 66. 4068-4073.

Kim, D.H., Heo, G.S. and Lee, D.W. (1998). Determination of organophosphorus pesticides in wheat flour by supercritical fluid extraction and gas chromatography with nitrogen-phosphorus detection. J. Chromatogr. A. 824. 63-70.

Kubo, A., Yogo, A., Imashiro, F. and Terao, T. (1996). Deuterium NMR study of the glassy crystal pentachlorotoluene. Hadamard quadrupole-order exchange NMR. J. Phys. Chem. 100. 15933-15941.

Kaljurand, M. and Küllik, E. (1979). Continuous thermal volatilization analysis of polymers by gas chromatography with pseudo-random samples. J. Chromatogr. 171. 243-247.

Kaljurand, M., Urbas, E. and Haldna, U. (1992). Characteristics and application of an electrochemical concentration modulator in correlation chromatography. Chromatographia. 34. 417-420.

Lehotay, S.J. (1997). Supercritical fluid extraction of pesticides in foods. J. Chromatogr. A. 785. 289-312.

Lub, T.T., Smit, H.C. and Poppe, H. (1978). Correlation high-performance liquid chromatography: a technique for improving the detection limit applied to the analysis of phenols. J. Chromatogr. 49. 721-733.

Laeven, J.M., Smit, H.C. and Kraak, J.C. (1983). An improved injection device for quantitative cross-correlation high-performance liquid chromatography at ultratrace levels. Anal. Chim. Acta. 150. 253-258.

Lin, C.H. and Imasaka, T. (1993). High-temperature pulsed slit nozzle for supersonic jet spectrometry. Rev. Sci. Instrum. 64. 3026-3027.

Mastovska, K., Dorweiler, K.J., Lehotay, S.J., Wegscheid, J.S. and Szpylka, K.A. (2010). Pesticide multiresidue analysis in cereal grains using modified QuEChERS method combined with automated direct sample introduction GC-TOFMS and UPLCMS/MS techniques. J. Agric. Food Chem. 58. 5959-5972.

Mei, E., Chen, G. and Zeng, Y. (1996). Hadamard transform microscope fluorescence image. Microchem. J. 53. 316-325. 
Mars, C. and Smit, H.C. (1990). Sample introduction in correlation liquid chromatography application, properties and working conditions for a novel injection system. Anal. Chim. Acta. 228. 193-208.

Pareja, L., Fernández-Alba, A.R., Cesio, V. and Heinzen H. (2011a). Analytical methods for pesticide residues in rice. Trends Anal. Chem. 30. 270-291.

Pareja, L., Cesio, V., Heinzen, H. and Fernández-Alba A.R. (2011b). Evaluation of various QuEChERS based methods for the analysis of herbicides and other commonly used pesticides in polished rice by LC-MS/MS. Talanta. 83. 1613-1622.

Seger, C., Römpp, H., Sturm, S., Haslinger, E., Schmidt, P.C. and Hadacek, F. (2004). Characterization of supercritical fluid extracts of St. John's Wort (Hypericum perforatum L.) by HPLC-MS and GC-MS. J. Pharm. Sci. 21. 453-463.

Stolker, A.A.M., Tricht, E.F., Zoontjes, P.W., van Ginkel, L.A. and Stephany, R.W. (2003). Rapid method for the determination of stanozolol in meat with supercritical fluid extraction and liquid chromatography-mass spectrometry. Anal. Chim. Acta. 483. 1-9.

Szumlas, A.W., Ray, S.J. and Hieftje, G.M. (2006). Hadamard transform ion mobility spectrometry. Anal. Chem. 78. 4474-4481.

Smit, H.C. (1970). Random input and correlation methods to improve the signal-to-noise ratio in chromatographic trace analysis. Chromatographia. 3. 515-518.

Smit, H.C., Lub, T.T. and Vloon, W.J. (1980). Application of correlation digh-performance liquid chromatography to the revfrse-phase separation of traces of chlorinated phenols. Anal. Chim. Acta. 122. 267-277.

Trapp, O., Kimmel, J.R., Yoon, O.K., Zuleta, I.A., Feranadez, F.M. and Zare, R.N. (2004). Continuous two-channel time-of-flight mass spectrometric detection of electrosprayed ions. Angew. Chem., Int. Ed. 43. 6541-6544.

Treado, P.J., Govil, A., Morris, M.D., Sternitzke, K.D. and McCreery, R.L. (1990). Hadamard transform raman microscopy of laser-modified graphite electrodes. Soc. Appl. Spetrosc. 44. 1270-1275.

Tang, H., Chen, G., Zhou, J. and Wu, Q. (2002). Hadamard transform fluorescence image microscopy using one-dimensional movable mask. Anal. Chim. Acta. 468. 27-34.

Wang, S.P. and Chang, C.L. (1998). Determination of parabens in cosmetic products by supercritical fluid extraction and capillary zone electrophoresis. Anal. Chim. Acta. 377. 85-93. 


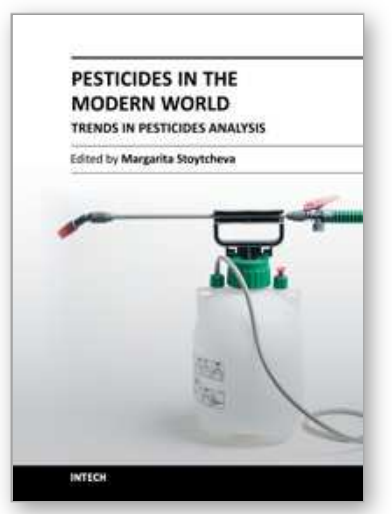

\author{
Pesticides in the Modern World - Trends in Pesticides Analysis \\ Edited by Dr. Margarita Stoytcheva
}

ISBN 978-953-307-437-5

Hard cover, 514 pages

Publisher InTech

Published online 21, October, 2011

Published in print edition October, 2011

The book offers a professional look on the recent achievements and emerging trends in pesticides analysis, including pesticides identification and characterization. The 20 chapters are organized in three sections. The first book section addresses issues associated with pesticides classification, pesticides properties and environmental risks, and pesticides safe management, and provides a general overview on the advanced chromatographic and sensors- and biosensors-based methods for pesticides determination. The second book section is specially devoted to the chromatographic pesticides quantification, including sample preparation. The basic principles of the modern extraction techniques, such as: accelerated solvent extraction, supercritical fluid extraction, microwave assisted extraction, solid phase extraction, solid phase microextraction, matrix solid phase dispersion extraction, cloud point extraction, and QuEChERS are comprehensively described and critically evaluated. The third book section describes some alternative analytical approaches to the conventional methods of pesticides determination. These include voltammetric techniques making use of electrochemical sensors and biosensors, and solid-phase spectrometry combined with flow-injection analysis applying flow-based optosensors.

\title{
How to reference
}

In order to correctly reference this scholarly work, feel free to copy and paste the following:

Cheng-Huang Lin and Chien-Hung Lin (2011). Applications of Hadamard Transform-Gas Chromatography/Mass Spectrometry (HT-GC/MS) to the Detection of Pesticides in Rice, Pesticides in the Modern World - Trends in Pesticides Analysis, Dr. Margarita Stoytcheva (Ed.), ISBN: 978-953-307-437-5, InTech, Available from: http://www.intechopen.com/books/pesticides-in-the-modern-world-trends-in-pesticidesanalysis/applications-of-hadamard-transform-gas-chromatography-mass-spectrometry-ht-gc-ms-to-thedetection-of

\section{INTECH}

open science | open minds

\section{InTech Europe}

University Campus STeP Ri

Slavka Krautzeka 83/A

51000 Rijeka, Croatia

Phone: +385 (51) 770447

Fax: +385 (51) 686166

\section{InTech China}

Unit 405, Office Block, Hotel Equatorial Shanghai

No.65, Yan An Road (West), Shanghai, 200040, China 中国上海市延安西路65号上海国际贵都大饭店办公楼 405 单元

Phone: +86-21-62489820

Fax: +86-21-62489821 
www.intechopen.com 
(C) 2011 The Author(s). Licensee IntechOpen. This is an open access article distributed under the terms of the Creative Commons Attribution 3.0 License, which permits unrestricted use, distribution, and reproduction in any medium, provided the original work is properly cited. 